\title{
ST Segment Elevation Right Ventricular Myocardial Infarction due to Isolated Right Ventricular Branch Occlusion During Right Coronary Artery Stenting
}

Musuraca Gerardo ${ }^{1 *}$, Agostoni $\mathrm{P}^{2}$, Terraneo $\mathrm{C}^{5}$, Di Matteo ${ }^{3}$, Boldi $\mathrm{E}^{4}$ and Albiero $\mathrm{R}^{4}$

${ }^{1}$ Division of Cardiology, S. Maria del Carmine Hospital, Rovereto, Italy

${ }^{2}$ Divsion of Cardiology, University Medical Center Utrecht, Utrecht, The Netherlands

${ }^{3}$ Department of Clinical and Experimental Med., Policlinico Hospital, University of Messina, Italy

${ }^{4}$ Division of Cardiology, Clinica S. Rocco di Franciacorta, Ome, Italy

${ }^{5}$ Division of Cardiology, Policlinico Hospital, Monza, Italy

\begin{abstract}
Isolated right ventricular (RV) myocardial infarction (MI) is an extremely rare phenomenon and may be difficult to recognize. Also, it is rare to observe ST elevation in anterior leads caused by isolated, transient small acute marginal branch occlusion. We described the case of an acute RV MI with transient ST segment elevation in precordial leads from $\mathrm{V} 1$ to $\mathrm{V} 4$, due to isolated $\mathrm{RV}$ branch occlusion during right coronary artery stenting.
\end{abstract}

Keywords: Myocardial anterior infarction; ST elevation due transient acute marginal branch occlusion; Right coronary artery stenting

\section{Introduction}

A 60-year-old male patient was admitted to our Hospital with a 1 -year history of chest pain. The electrocardiogram showed minimal ST depression in the anterior leads due to an old anterior myocardial infarction 10 years before (Figure 1).

Physical examination was normal. A two-dimensional echocardiography showed severe hypokinesia of the anterior left ventricular wall and normal right ventricular function.

The day after, a coronary angiography revealed critical stenosis of the middle right coronary artery (RCA) and a severely stenotic (but patent) small right ventricular (RV) branch (Figure 2), a normal left anterior descending artery (LAD), a critical stenosis of a first large diagonal branch, and a normal left circumflex artery (Figure 3).

A coronary angioplasty was successfully performed with implantation of a drug eluting stent (Xience Prime $3.5 \times 23 \mathrm{~mm}$ ) in the middle part of RCA. Total occlusion of the small RV branch occurred (Figure 4).

The patient experienced chest pain and an electrocardiogram taken just after stent implantation showed $3 \mathrm{~mm}$ ST segment elevation in precordial leads V1 to V4 and leads V3R to V5R (Figure 5). A new two- dimensional echocardiography showed no evidence of new left ventricular anterior wall motion abnormalities than those seen at baseline and no septum involvement, but only limited hypokinesia of the RV wall.

Angiography was repeated and showed a successful result of the stent with occlusion of the RV branch and al left coronary system with the same stenosis in the first diagonal branch, as shown already in the first angiogram (Figure 4).

The operator decided to open the RV branch again by means of a balloon-only angioplasty, with good result. The chest pain was then resolved and ST segment elevation in leads V1 to V4 and in leads V3R to V5R disappeared.

The patient remained asymptomatic during in-hospital follow-up.

\section{Discussion}

This case describes the occurrence of ST segment elevation in precordial leads V1 to V4, with ST segment elevation of V1>V3, due to isolated RV branch occlusion, occurring during RCA angioplasty in a patient undergoing elective PCI.

Right ventricular myocardial infarction (MI) is normally

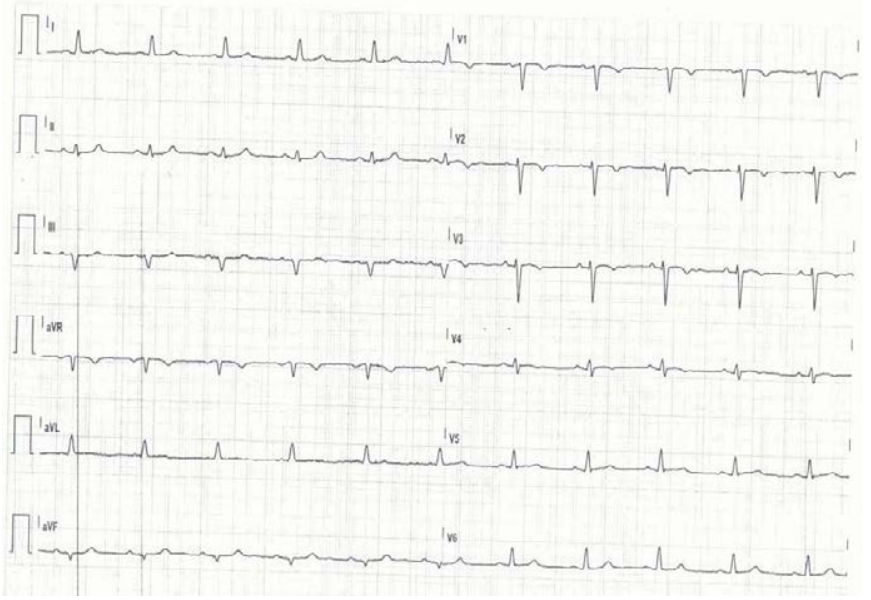

Figure 1: The basal Ecg shows normal ST-T segment in the inferior leads and minimal ST segment depression in the precordial leads.

*Corresponding author: Musuraca Gerardo, Division of Cardiology, S. Maria de Carmine Hospital, U.O. Cardiology, viale Verona, Rovereto, Trento 38068, Italy, Tel: 00390464403428; E-mail: musuraca@yahoo.it

Received January 13, 2014; Accepted February 06, 2014; Published February 13, 2014

Citation: Gerardo M, Agostoni P, Terraneo C, Di Matteo I, Boldi E, et al. (2014) ST Segment Elevation Right Ventricular Myocardial Infarction due to Isolated Right Ventricular Branch Occlusion During Right Coronary Artery Stenting. J Cardiovasc Dis Diagn 2: 144. doi:10.4172/2329-9517.1000144

Copyright: @ 2014 Gerardo M, et al. This is an open-access article distributed under the terms of the Creative Commons Attribution License, which permits unrestricted use, distribution, and reproduction in any medium, provided the original author and source are credited. 
Citation: Gerardo M, Agostoni P, Terraneo C, Di Matteo I, Boldi E, et al. (2014) ST Segment Elevation Right Ventricular Myocardial Infarction due to Isolated Right Ventricular Branch Occlusion During Right Coronary Artery Stenting. J Cardiovasc Dis Diagn 2: 144. doi:10.4172/23299517.1000144

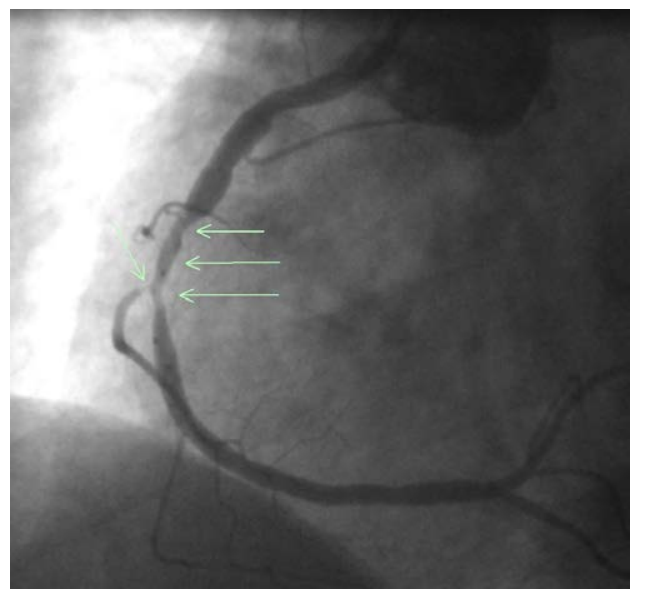

Figure 2: Selective coronary arteriography $\left(0^{\circ}\right.$ antero-posterior $30^{\circ}$ left view) shows the critical stenosis in the middle right coronary artery and the ostial sub-occlusion of the right ventricular branch (arrows).

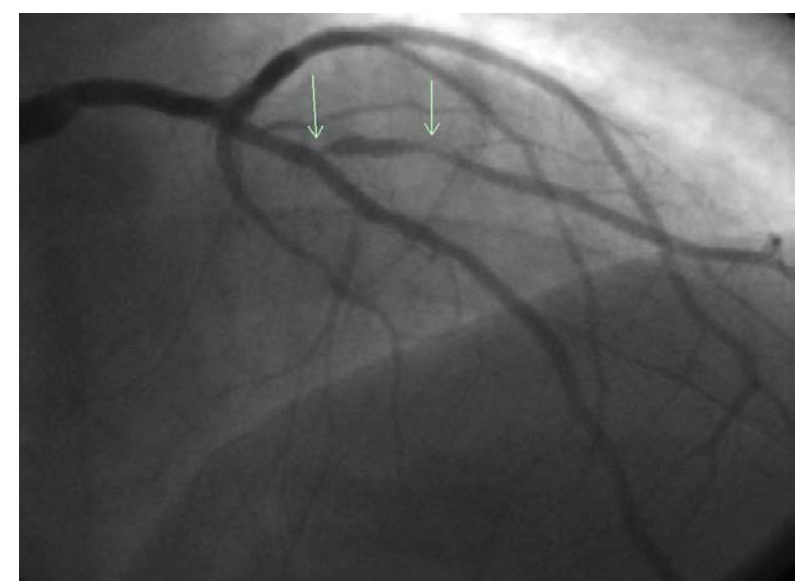

Figure 3: Selective coronary arteriography $\left(40^{\circ}\right.$ cranial $0^{\circ}$ antero-posterior view) shows the critical, double stenosis in the first diagonal branch of the left anterior descending coronary artery (arrows).

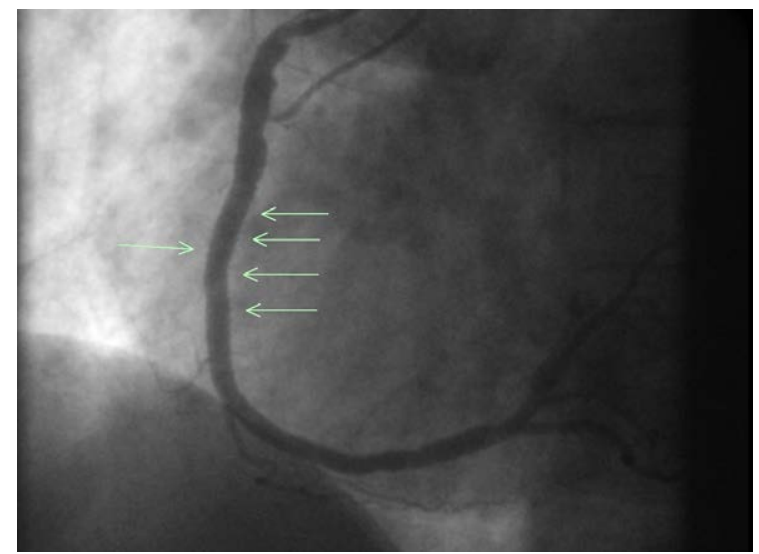

Figure 4: Selective coronary arteriography $\left(0^{\circ}\right.$ antero-posterior $30^{\circ}$ left view) shows the stent implantation of the middle right coronary artery (multiple arrows) and the post-stenting occlusion of the right ventricular branch (single arrow).

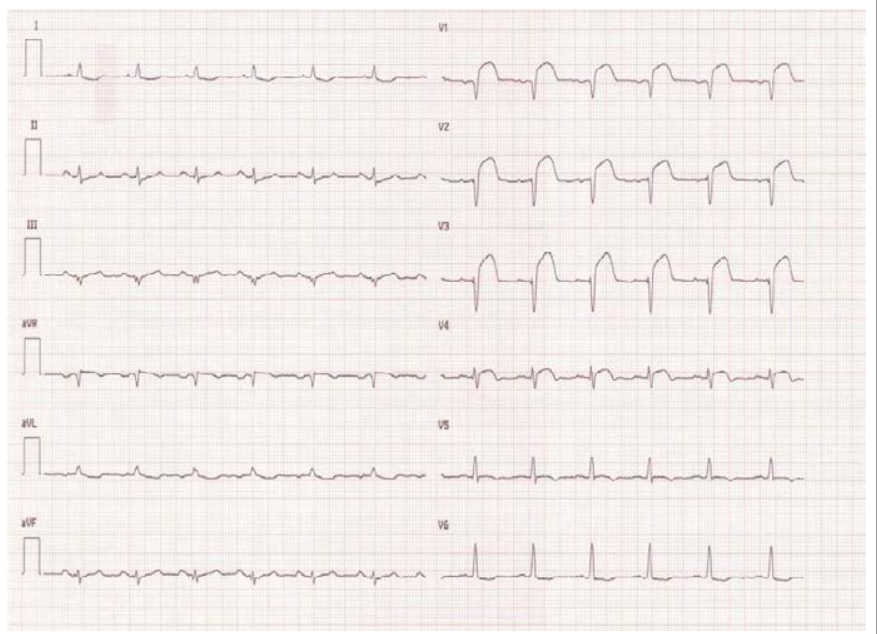

Figure 5: The Ecg during $\mathrm{PCl}$ shows the ST elevation in V1-V4 due to transient occlusion of the right ventricular branch. The ST remains normal in the inferior leads.

diagnosed by ST segment elevation $>1 \mathrm{~mm}$ in leads V3R to V6R. In the presence of acute inferior MI, ST segment elevation of $1 \mathrm{~mm}$ or more in the right-sided precordial leads, especially in V3R, was found to be diagnostic of right ventricular MI with a positive diagnostic value of 79-100\% [1]. Classically, ST segment elevation in precordial leads V1 to V3-V4 is characteristic of anterior left ventricular MI secondary to LAD occlusion, but generally if the ST elevation of $\mathrm{V} 1>\mathrm{V} 3$ the ischemic problem can be due to isolated occlusion of an RV branch [2].

In our case, the $\mathrm{LAD}$ and its septal branches were normal; the first diagonal had a critical stenosis but not an acute occlusion during the procedure.

In the literature, ST segment elevation instead of reciprocal ST depression in precordial leads V1 to V3 has been described in patients with RV MI in association with acute inferior MI $[3,4]$. In the presence of coexisting acute RV injury and dilatation, ST segment elevation may be seen in the anteriorly oriented precordial leads V1 to V3-V4, because a larger part of the RV free wall is directed anteriorly. Using an experimental MI model, Geft et al. found evidence that the ST segment elevation in the left precordial leads was dependent on the coexisting electrical forces ratio between the ischemic RV free wall and the left ventricular inferior wall [3].

Isolated RV MI yielded an ST segment elevation in the precordial leads, whereas its combination with inferior left ventricular MI suppressed this ST segment elevation in the precordial leads and yielded an ST segment elevation in leads II, III, and a VF.

The ECG of our case showed, during PCI, no reciprocal ST segment depression in anterior derivations and ST elevation only in V1-V4 leads. In the occurrence of anterior ST segment depression during acute inferior MI, the proposed explanations vary from extensive inferoposterior infarction or additional anterior ischemia to a reciprocal change [5-7].

In our case, there was no new anterior ischemia and, in addition, no echocardiographic and clinical findings of extensive inferior MI, but only in a transient ischemic low RV part. During the angioplasty, ST segment elevation only in precordial leads V1 to V4 was due to isolated occlusion of a RV branch. 
Citation: Gerardo M, Agostoni P, Terraneo C, Di Matteo I, Boldi E, et al. (2014) ST Segment Elevation Right Ventricular Myocardial Infarction due to Isolated Right Ventricular Branch Occlusion During Right Coronary Artery Stenting. J Cardiovasc Dis Diagn 2: 144. doi:10.4172/23299517.1000144

Page 3 of 3

Van der Bolt et al. Observed that isolated acute occlusion of the RV branch after angioplasty could be followed by ST segment elevations in leads V1 to V3 [8]. Sonoda et al. have reported that ST segment elevation in the precordial leads occurred in a reproducible manner when the balloon occluded the RV branch [9]. Hence, our case confirms previous studies and observations that ST segment elevation in precordial leads V1 to V4 may be a rare sign of RV branch occlusion.

This explains that, from an electrocardiographic perspective, RV MI may occur also because of isolated RV branch occlusion in the absence of inferior electrocardiographic changes $[9,10]$.

In conclusion, patients who develop transient ST segment elevation in precordial leads $\mathrm{V} 1$ to $\mathrm{V} 3 / \mathrm{V} 4$ especially with ST elevation of $\mathrm{V} 1>\mathrm{V} 3$, during or following RCA angioplasty, should not be assumed to have LAD occlusion, since the RV branch may be responsible for this phenomenon.

\section{References}

1. Kinch JW, Ryan TJ (1994) Right ventricular infarction. N Engl J Med 330: 1211 1217.

2. Vives MA, Bonet LA, Soriano JR, Lalaguna LA, Sáez AO, et al. (1999) Righ ventricular infarction mimicking anterior infarction: a case report. J Electrocardiol 32: 359-363.

3. Geft IL, Shah PK, Rodriguez L, Hulse S, Maddahi J, et al. (1984) ST elevations in leads V1 to V5 may be caused by right coronary artery occlusion and acute right ventricular infarction. Am J Cardiol 53: 991-996.

4. Lopez-Sendon J, Coma-Canella I, Alcasena S, Seoane J, Gamallo C (1985) Electrocardiographic findings in acute right ventricular infarction: sensitivity and specificity of electrocardiographic alterations in right precordial leads V4R, V3R, V1, V2 and V3. J Am Coll Cardiol 6: 1273-1279.

5. Khan ZU, Chou TC (1996) Right ventricular infarction mimicking acute anteroseptal left ventricular infarction. Am Heart J 132: 1089-1093.

6. Gibelin P, Gilles B, Baudouy M, Guarino L, Morand P (1986) Reciprocal ST segment changes in acute inferior myocardial infarction: clinical, haemodynamic and angiographic implications. Eur Heart J 7: 133-139.

7. Lew AS, Maddahi J, Shah PK, Weiss AT, Peter T, et al. (1985) Factors that determine the direction and magnitude of precordial ST-segment deviations during inferior wall acute myocardial infarction. Am J Cardiol 55: 883-888.

8. Van der Bolt CL, Vermeersch PH, Plokker HW (1996) Isolated acute occlusion of a large right ventricular branch of the right coronary artery following coronary balloon angioplasty: the only true "model" to study ECG changes in acute, isolated right ventricular infarction. Eur Heart J 17: 247-250.

9. Sonoda M, Keigo T, Hizukuri K, Tanaka H, Tsunenari H, et al. (2001) Transient but marked ST elevation in precordial leads caused by ischemia of the isolated right ventricular branch. Jpn Circ J 65: 129-131.

10. Mahmut Acikel, Mustafa Yilmaz, Engin Bozkurt, Yekta Gurlertop, Nuri Kose (2003) ST Segment Elevation in Leads V1 to V3 Due to Isolated Right Ventricular Branch Occlusion During Primary Right Coronary Angioplasty. Catheterization and Cardiovascular Interventions 60: 32-35. 